\title{
Modeling the Effects of the Factors Affecting IGF in Coastal Areas and Variation of IGF in Jiaodong Peninsula of China Based on Finite Element Method
}

Hong-Xu Chu

Shandong University at Weihai

Zan-Yang Xing ( $\nabla$ xingzanyang@sdu.edu.cn )

Shandong Medical Institute: Shandong University https://orcid.org/0000-0001-5965-1017

Yan-Ling Wang

Shandong University at Weihai

Balan Nanan

Shandong University at Weihai

Qing-He Zhang

Shandong University

Li-Kai Liang

Shandong University at Weihai

Han Wang

Shandong University at Weihai

\section{Research Article}

Keywords:

Posted Date: January 27th, 2022

DOI: https://doi.org/10.21203/rs.3.rs-1096104/v2

License: (c) (1) This work is licensed under a Creative Commons Attribution 4.0 International License.

Read Full License 


\section{Abstract}

Based on finite element method, we develop a model of the induced geoelectric field (IGF) occurring in land-sea boundary regions during large geomagnetic field disturbances. The model is used first to study the effects of the changes in the lithospheric conductivity, ionospheric current, and ocean depth on the distribution of IGF in a typical land-sea boundary region. The results show that the changes in the lithospheric conductivity and ionospheric current (frequency, magnitude and direction) have major effects and ocean depth has minor effect on IGF in coastal areas. Then by incorporating a realistic 3-D conductivity variation of Jiaodong Peninsula (JDP) in China obtained from measured data, the model is used to simulate the IGF variation in JDP covering its land-sea boundaries for east-west and north-south ionospheric currents. The results show a new aspect that extremely large IGF development on the land side of the coastal bay areas perpendicular to the currnet compared to plane coastal areas. The results can stimulate detailed investigations of IGF (and GIC, geomagnetically induced current) in coastal areas.

\section{Key Points}

- Finite element method is used to model the effects on IGF of the changes in coastal conductivity, ionospheric current and ocean depth.

- The changes in the conductivity and ionospheric current and frequency are found to be the major factors affecting IGF in coastal areas.

- The IGF modeled using the observed conductivity values in coastal bay areas are over twice as strong as in plane areas.

\section{Plain Language Summary}

During space weather, the high-energy solar wind with frozen-in magnetic field interact with the Earth's magnetosphere-ionosphere system, causing violent fluctuations in the geomagnetic field and induced geoelectric field (IGF) and geomagnetically induced current (GIC) in ground-based

systems especially in coastline areas. IGF and GIC increase the reactive power loss of power transmission systems and even cause transformer failure. It has therefore been important to investigate the effects on IGF of the changes in coastal conductivity, ionospheric current frequency and strength, and ocean depth in sea-land boundaries. In this paper, using a newly developed conductivity model we first investigate the effects of these changes on IGF in a typical sea-land boundary and then study the IGF variation in the coastal area of Jiaodong Peninsula in China using observed conductivities. The results show a new aspect that IGF in bay boundaries are over twice as strong as in plane boundaries.

\section{Introduction}

Large geomagnetic disturbances caused by solar storms such as ICMEs (interplanetary coronal mass ejections) are known to produce induced geoelectric field (IGF) in the earth, ocean and other conducting 
media. IGF causes geomagnetically induced current (GIC) flow in the electrical loop formed by the utility systems such as electric power grids, telecommunication networks, etc. and the earth. The systems get damaged when GIC exceeds their tolerance limit (Wang, 2003; Kappaenman, 1996, 2003;Wang et al., 2021)[1-3].

GIC is generally strong at high latitudes due to the strong geomagnetic field there undergoing large and violent changes during space weather events. Many GIC related utility system damages happened in the high latitude regions such as Northern Europe and North America during severe space weather events. For example, the event on 13 March 1989 damaged the Quebec power transformer causing power outage for over five million people for over nine hours (Kappaenman \& Albertson, 1990; Pulkkinen et al., 2005). In recent years, China, Australia, New Zealand, Japan and other countries in middle and low latitudes have also experienced GIC infringements in power grids (Cui et al., 2010; Wu \& Liu., 2013; Liu et al., 2016; Marshall et al., 2013; Clilverd et al., 2020; Shigeru et al., 2018). Studies also found that coastal areas are more prone to GIC impacts than inland areas. For example, in December 2006, significant levels of GIC were detected in the Guangdong Lingao and Jiangsu Shanghe substations in China. Comparative studies during the event showed that the GIC level in the lower latitude substation (Guangdong Lingao) was larger than that in the higher latitude substation (Jiangsu Shanghe) (Liu et al., 2009) due to the "coast effect". That is, the electrical conductivity in coastal areas (Guangdong Lingao) are stronger and more complex than in inland areas (Jiangsu Shanghe) (Fernberg et al., 2007).

Though the main cause of IGF is solar storms such as ICMEs, the distribution of IGF in the earth depends on the electrical properties of the earth. Studying the influence of the electrical structure of the earth on the distribution of IGF is therefore the key to assess the GIC level in power grids, which have been undertaken by many scientific groups. In the earlier calculations of IGF distribution, scientists have used the plane wave method (Viljanen et al., 2006) and complex image method (Pulkkinen et al., 2007). These methods considered the earth as a horizontally layered one-dimensional structure and ignored the lateral changes of earth's conductivity. The methods therefore are not suitable for calculating the IGF distribution in coastal areas having large lateral conductivity changes.

Recently, scientists have used two-dimensional earth conductivity models to calculate the IGF generated in coastal areas. It is found that IGF has increased greatly in the land area up to about $50 \mathrm{~km}$ away from the sea-land interface. This has been explained in terms of the coastal effect, that is, the distribution of IGF is greatly affected by the lateral change of the earth's conductivity (Olsen \& Kuvshinov, 2004; Gilbert, 2005). Liu et al. (2016; 2017) developed an one-dimensional (1-D) and three-dimensional (3-D) geodetic conductivity models for the local area along the coast of Guangdong Lingao, and calculated the IGF during the super the geomagnetic storm on November 9, 2004. The accuracy of the GIC value calculated by the 3D model of IGF is $18 \%$ higher than that by the $1 \mathrm{D}$ model. But there is still a gap of $12 \%$ compared with the measured data (Liu et al., 2016; 2017). The reason for the difference between the 3D model and data may be due to the insufficient fitting of the Earth's electrical structure. 
In this article, we use an effective numerical calculation method - the finite element method - to develop a 3D earth conductivity model in the sea-land boundary region and calculate the geomagnetic field and IGF. The finite element method has a very wide range of applications in successfully reflecting the structural relationship of complex materials and calculations in the field of electromagnetic fields. It has better performance than other numerical calculation methods in dealing with complex free boundary conditions. Since the complex geodetic conductivity model involves the connections of many boundaries of different conductivity regions, the free boundary conditions are very complicated. The finite element method can well solve the problem of handling these free boundary conditions. The 3D model is used first to study the effects of lithospheric conductivity, ionospheric current (frequency, magnitude and direction), and ocean depth on the distribution of IGF in a typical land-sea boundary region. Then the 3D model is extended to construct a conductivity model for the land-sea boundary area of the Jiaodong Peninsula (JDP) in China by using the measured data of the geological environment of Jiaodong Peninsula (JDP). The 3D model is uded to simulate the distribution of IGF in JDP under east-west and north-south currents.

\section{Mathematical Model Of Igf}

As mentioned above, we use the finite element method to develop a mathematical model of the induced geoelectric field (IGF). Two assumptions (Honkonen et al., 2018) are used in the model. (1) Rotation and curvature of the earth are ignored and modeling and analysis are performed in Cartesian coordinate system. (2) The magnetic permeability in all solution domains is assumed to be the vacuum magnetic permeability $\mu_{0}\left(=4 \pi \times 10^{-7} \mathrm{H} / \mathrm{m}\right)$. The assumptions are valid for calculating IGF especially in local areas such as JDP.

Figure 1 illustrates the IGF mathematical model. The whole solution domain $\Omega$ is divided into the conductor area $\Omega_{1}$, non-conductor area $\Omega_{2}$, and interface $\Gamma$. The conductor area $\Omega_{1}$ is composed of the conductive earth, sea water and other geological structures. The non- conductor area $\Omega_{2}$ is composed of air and ionospheric current source $J_{s}$. The interface $\Gamma$ between $\Omega_{1}$ and $\Omega_{2}$ is the surface of the earth shown by the horizontal line. $e_{n}$ is a unit vector normal to the interface $\Gamma$ directed from $\Omega_{1}$ to $\Omega_{2}$. Based on the physical properties of the electromagnetic field, properties of the medium and boundary constraints, the finite element method is used first to mesh the solution domain, that is, divide the domain into sub-units. Then, refine the mesh at the interface where the electrical conductivity changes greatly, and coarsen the mesh at the areas where the electrical conductivity is uniform.

In order to simplify the calculation of the three-dimensional geoelectric field, the vector magnetic potential $\vec{A}$ and scalar magnetic potential $\phi$ are used as the functions to be calculated at each node of the subunit. The geomagnetic field $\vec{B}$ and the geoelectric field $\vec{E}$ are expressed as:

$$
\vec{B}=\nabla \times \vec{A}
$$


Istackrel \{\} $\mid E\}=-(\backslash$ frac $\{? \backslash$ stackrel \{\}$\{A\}\} ?$ t\}+?f)

2

The basic equation of the three-dimensional IGF mathematical model is (Ma, 2016):

$\backslash$ frac $\{1\}\{\{\backslash m u\}\{\{0\}\} \backslash$ nabla \times \nabla \times \overrightarrow $\{A\}+\backslash$ sigma $\backslash$ left $(\backslash f r a c\{\backslash p a r t i a l$ loverrightarrow $\{A\}\}\{$ partial $t\}+\backslash$ nabla $\backslash$ phi $\backslash$ right $)=\backslash$ overrightarrow $\left\{\{J\} \_\{s\}\right\}$

3

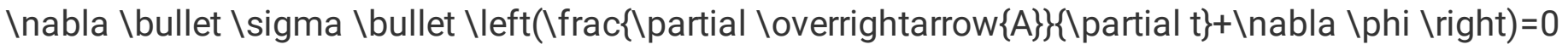
4

where $\{\backslash$ sigma $\}$ is the conductivity of the conductive medium.

The interface conditions of different conductivity regions are:

$\{e\}_{-}\{n\} \backslash$ times $\backslash$ eft $\left(\backslash\right.$ frac $\{1\}\left\{\{\backslash m u\}_{-}\{0\}\right\} \backslash$ nabla $\backslash$ times $\backslash$ overrightarrow $\left\{\{A\}_{-}\{2\}\right\}-\backslash$ frac $\{1\}\left\{\{\backslash m u\}_{-}\{0\}\right\} \backslash$ nabla \times \overrightarrow $\left\{\left\{A_{-}\{1\}\right\} \backslash\right.$ right $)=0$

5

loverrightarrow $\left.\{A\}_{-}\{2\}\right\}=\backslash$ overrightarrow $\left\{\{A\}_{-}\{1\}\right\}$

6

$\{\mid \text { phi }\}_{-}\{2\}=\{\mid \text { phi }\}_{-}\{1\}$

7

$\{e\}_{-}\{n\} \backslash$ bullet $\{\backslash \text { sigma }\}_{-}\{2\} \backslash$ left $\left(\backslash\right.$ frac $\left\{\backslash\right.$ partial $\backslash$ overrightarrow $\left.\left\{\{A\}_{-}\{2\}\right\}\right\} \backslash$ partial $\left.t\right\}+\backslash$ nabla $\{\backslash p h i\}_{-}\{2\} \backslash$ right $)=$ $\{e\}_{-}\{n\} \backslash$ bullet $\{\backslash \text { sigma }\}_{-}\{1\} \backslash$ eft $\left(\backslash\right.$ frac $\left\{\backslash\right.$ partial $\backslash$ overrightarrow $\left.\left\{\{A\}_{-}\{1\}\right\}\right\}\{$ partial $t\}+\backslash$ nabla $\left.\{\backslash p h i\}\{1\}\right\} \backslash$ right $)$ 8

$\{\backslash \text { sigma }\}_{-}\{1\}$ and $\{\backslash \text { sigma }\}_{-}\{2\}$ are the conductivities, $\{A\}_{-}\{1\}$ and $\{A\}_{-}\{2\}$ are the vector magnetic potentials, and $\{\backslash \text { phi }\}_{-}\{1\}$ and $\{\backslash p h i\}_{-}\{2\}$ are the scalar magnetic potentials of the land and sea, respectively.

The boundary of the earth conductor area satisfies the first boundary condition:

loverrightarrow $\left\{\{A\} \_\{2\}\right\}=\backslash$ overrightarrow $\left\{\{A\}_{-}\{0\}\right\}$

9

The boundary of the air area satisfies the second boundary condition:

$\{e\}_{-}\{$n $\} \backslash$ times $\backslash$ left $\left(\backslash\right.$ frac $\left.\{1\}\{\backslash \backslash m u\}_{-}\{0\}\right\} \backslash$ nabla \times

loverrightarrow $\left\{\{A\}_{\_}\{2\}\right\} \backslash$ right $)=\backslash$ overrightarrow $\left\{\{K\}_{-}\{0\}\right\}$

10

Equation 10 specifies the tangent component of the geomagnetic field as the boundary condition and applies in the form of surface current density \overrightarrow $\left\{\{K\}_{-}\{0\}\right\}$. The ground serves as the interface 
between the earth conductor and the air area (Figure 1). According to current continuity at the interface, there is

$\{e\}_{-}\{\mathrm{n}\} \backslash$ bullet $\backslash$ sigma $\backslash$ times $\backslash$ left $(\backslash$ frac $\{\backslash$ partial $\backslash$ overrightarrow $\{A\}\} \backslash$ partial $t\}+\backslash$ nabla $\backslash$ phi $\backslash$ right $)=0$ 11

Equations (3) to (11) are the basic equations and boundary conditions of the 3-D geoelectric field boundary value problem in time domain. When the specific forms of the current source $J_{s}$ in $\Omega_{2}$ and the conductivity distribution in $\Omega_{1}$ are given, the \overrightarrow $\{A\}$ and $\{\backslash p h i\}$ of each node of any sub-unit in the field can be obtained. Then when all the sub-units are combined, the \overrightarrow $\{B\}$ and loverrightarrow $\{E\}$ in the solution domain are obtained from formulas (1) and (2). We use the AC/DC module in the COMSOL AB Multiphysics $®$ v.5.4. software developed at Stockholm in Sweden and available at cn.comsol.com to calculate and simulate the ground conductivity and IGF distribution.

\section{Model Setup}

In the modeling procedure, the conductivity of land and seabed is set to a typical value of $0.01 \mathrm{~S} / \mathrm{m}$ up to $100 \mathrm{~km}$ below the surface since both land and seabed belong to the lithosphere. Taking into account the skin effect of the electromagnetic field, the skin depth is calculated for a surface current of frequency of $0.003 \mathrm{~Hz}$ and current density $100 \mathrm{~A} / \mathrm{m}^{2}$ in the ground with a conductivity of $0.01 \mathrm{~S} / \mathrm{m}$. The calculation results show that the electromagnetic field at a depth of $400 \mathrm{~km}$ is $\sim 1 \%$ of the surface electromagnetic field. Therefore, the lower boundary of the model is set at a depth of $400 \mathrm{~km}$. In order to avoid the influence of the lateral boundary conditions on the IGF, the left and right boundaries are set at $500 \mathrm{~km}$ from the center. At the lateral tion boundaries, the electromagnetic wave is complteley absorbed though theoretically the boundary can extend to infinity.

The ocean depth is set at $4 \mathrm{~km}$ considering the average global ocean depth of $3688 \mathrm{~m}$, and the ocean conductivity is set at $4 \mathrm{~S} / \mathrm{m}$, the average conductivity of sea water. Since geomagnetic disturbances arise mainly from the changes in the storm-time ionospheric current, these disturbances are simulated by assuming the current. Following Pulkkinen et al. (2007), the current is considered as a thin uniform current sheet at a height of $100 \mathrm{~km}$ above the earth's surface. Assuming that the ionospheric current frequency is $0.003 \mathrm{~Hz}$, the surface current density is set at $100 \mathrm{~A} / \mathrm{m}^{2}$. The surface current in the model starts from the boundary on one side to the boundary on the corresponding side, which is a continuous current that runs through the entire model. The ionospheric current generates magnetic waves propagating down to the earth and induces the geoelectric field. To simulate the attenuation effect of air on the waves, the atmospheric conductivity is set at $1.8 \times 10^{-4} \mathrm{~S} / \mathrm{m}$ in the region between the ionospheric current and earth surface. The upper boundary of the model is set $50 \mathrm{~km}$ above the sheet current, and electromagnetic waves are completely absorbed at the boundary. Figure 2(a) shows the ground conductivity model of the land-sea boundary area. Figures 2(b) and 2(c) display the calculated underground ( $X-Z$ plane with $Y=0$ ) magnetic field and IGF, and Figures 2(d) and 2(e) display the calculated surface $(X-Y$ plane with $Z=0)$ magnetic field and IGF, respectively. 
As shown by Figures $2 \mathrm{~b}$ and $2 \mathrm{~d}$, the magnetic field in the ocean area is concentrated on the ocean surface (reddish-yellow strip in Figure $2 \mathrm{~b}$ ) and does not extend much below the surface; the magnetic field in the land area, though weak at the surface, extends well below the surface. The IGF (Figures $2 \mathrm{c}$ and $2 e$ ) is concentrated within a small distance on the land side of the land-sea interface, with amplitude up to $115 \mathrm{mV} / \mathrm{km}$ at the center of the interface; beyond the small distance, IGF gradually decreases to nearly uniform value laterally. In the sea side there is almost no IGF. The main point in Figure 2 is the illustration of the 'coastal effect'. That is, IGF gets concentrated within a small area on the land side of the land-sea interface. The coastal effect therefore should be considered seriously in GIC risk assessment.

Comparing (a) and (b), it can be found that the distribution of IGF in the two figures is basically the same without considering the size and frequency of the sheet current. It shows that using this model to analyze the distribution of IGF is effective.

\subsection{Effects of different factors on IGF}

As mentioned in section 1, IGF is affected by many factors such as conductivity, ionospheric current (frequency, magnitude and direction), ocean depth, etc. The effects of these factors on IGF are investigated in this section.

\subsubsection{Effect of conductivity}

The conductivity of slate in common sedimentary rocks and metamorphic rocks are found to be in $\sim 0.001-0.1 \mathrm{~S} / \mathrm{m}$ range and quartzite in magmatic rocks and metamorphic rocks are in $\sim 0.0001-0.01 \mathrm{~S} / \mathrm{m}$ range. To cover these ranges, in the model (Figure 2a), we use the lithospheric conductivity in $\sim 0.0001-0.1$ $\mathrm{S} / \mathrm{m}$ range. Other conditions are same as in the model. As shown in Figures $4-5$, when the conductivity increases from 0.0001 to $0.1 \mathrm{~S} / \mathrm{m}$, in the land side the maximum IGF (IGFmax) at the center of the landsea interface decreases from $368.3 \mathrm{mV} / \mathrm{km}$ to $24 \mathrm{mV} / \mathrm{km}$. For all conductivity values, IGF decreases rapidly within a short distance and stabilizes gradually at a long distance from the interface (Figure 5). The stars indicate the distances ( 20-30 km) where IGF becomes $50 \%$ of IGFmax and dots indicate the distances ( 150-90 km) where IGF nearly stabilizes when conductivity increases from 0.0001 to 0.01 $\mathrm{S} / \mathrm{m}$. In the sea side, IGF suddenly decreases to a value of zero for all conductivities.

The fact that IGFmax decreases from high to low values (368 mV/km to $24 \mathrm{mV} / \mathrm{km}$ ) with the increase of lithospheric conductivity $(0.0001$ to $0.01 \mathrm{~S} / \mathrm{m})$ indicates that the conductivity is a major factor influencing the IGF in coastal areas. The greater the difference in electrical conductivity between land and ocean, the greater the magnitude of IGF generated in the land-sea boundary area, and the more severe the impact of the coastal effect.

\subsubsection{Effects of ionospheric current}

The ionospheric current during geomagnetic storms can affect IGF through changes in frequency, magnitude and direction. The effects of these aspects are studied here. The storm-time ionospheric 
current is found to have periodic variations with periods $~ 100-1000 s(X u, 2000)$. We use current of frequency $0.001-0.01 \mathrm{~Hz}$; all other conditions remain the same as in the model (Figure 2a).

The simulation results (Figures 6-7) show that IGFmax decreases rapidly from $153 \mathrm{mV} / \mathrm{km}$ to $52 \mathrm{mV} / \mathrm{km}$ when the current frequency increases from $0.001 \mathrm{~Hz}$ to $0.01 \mathrm{~Hz}$. The decrease of IGF with distance from the interface (Figure 7) is similar to that for the conductivity (Figure 5) though IGFmax for the current case is only about half. Stars and dots indicate the distance where IGF becomes $50 \%$ of IGFmax ( 25-65 $\mathrm{km}$ ) and nearly stabilizes ( 125-60 km), respectively, for frequency 0.001-0.006 Hz. Like conductivity, the ionospheric current frequency is a major factor influencing the strength IGF in coastal areas.

The effect of ionospheric current density on IGF is shown in Figure 8; (a), (b) and (c) are surface IGF for current density $50 \mathrm{~A} / \mathrm{m}^{2}, 100 \mathrm{~A} / \mathrm{m}^{2}$ and $200 \mathrm{~A} / \mathrm{m}^{2}$ with all other conditions same as in the model (Figure 2a). As shown, magnitude of IGFmax at the interface is nearly equal to that of current density indicting that the severity of IGF (and GIC) depends directly on the severity of storm-time ionospheric current. To study the effect of ionospheric current direction, the current $\left(100 \mathrm{~A} / \mathrm{m}^{2}\right)$ is changed to be parallel to the land-sea interface; all other conditions are same as for Figure 8b. In this case (Figure 8d), there is no IGF at the interface and IGF in inland areas is slightly decreased compared to when the current is perpendicular to the interface (Figure 8b). The results (Figure 8) indicate that IGF (and GIC) are strong in coastal areas where the current is perpendicular to the sea-land interface.

\subsubsection{Effect of ocean depth}

The ocean is generally considered to have two parts, the sea and ocean. The ocean is the main body which has a depth of $\sim 3-100 \mathrm{~km}$ and sea is the shallow ocean-land boundary having depth up to $3 \mathrm{~km}$. The coastal area includes the coastal land area and the adjacent sea-ocean boundary area. Considering that there is rarely any deep ocean in the sea-land boundary area, the ocean depth is set to vary from 1 to $3 \mathrm{~km}$. All other conditions remain the same as in the model (Figure 2a). There is only a small change in IGF (Figure 9) when ocean depth increases from 1 to $3 \mathrm{~km}$.

The corresponding IGFmax at the interface is found to decrease by a small amount from $139.2 \mathrm{mV} / \mathrm{km}$ to $100 \mathrm{mV} / \mathrm{km}$. With distance from the interface, the IGF rapidly decreases and becomes nearly constant at $\sim 50 \mathrm{~km}$ away from the interface for all ocean depths (line curves not shown). The results indicate that the ocean depth has only a minor effect on IGF.

\section{Modeling The Igf In Jiaodong Peninsula}

Jiaodong Peninsula (JDP, Figure 10a) is located in the north-eastern coastal area of China at (34.4区-38.4 $₫ \mathrm{~N}, 114.3 \rrbracket-122.7 \rrbracket \mathrm{E})$. In order to protect the power grids of JDP from getting damaged due to large GIC, it is necessary to analyze the distribution of IGF in JDP. As discussed in section 3, lithospheric conductivity has strong impacts on IGF distribution in coastal areas. We obtain a realistic conductivity model in JDP covering its land-sea boundaries and simulate the distribution of IGF in JDP. 
The electrical conductivity distribution map of JDP (Figure 10a) is obtained from China's deep geological section data set surveyed by the Institute of Geology (China Earthquake Administrator) and the China Environmental Geology zoning map drawn by the Institute of Hydrogeology and Environmental Geology (IHEG) of the Chinese Academy of Geological Sciences. The inset Table in Figure 10a lists the electrical conductivity distribution at different depths obtained for zones 1,2 and 3. By using the listed conductivity distribution (Figure 10a), we simulate the distribution of IGF in JDP for both east-west and north-south ionospheric currents. The other parameters used are same as those in model Figure 2a (ionospheric current density $100 \mathrm{~A} / \mathrm{m}^{2}$ and current frequency $0.003 \mathrm{~Hz}$ ) which seem to correspond to large geomagnetic disturbances.

Figures (10b-c) show the simulated ground magnetic field and IGF in JDP for eastward currents and Figures (10d-e) show the same for northward currents, respectively. The east-west and north-south ionospheric currents have generated strong geomagnetic field in the sea-land boundary areas especially on the south and north sides and east side (Figure 10b-d), respectively; the field in eastern boundary area (Figure 10b) and inland area are significantly weak. IGF amplitude for east-west ionospheric current (Figure 10c) is larger on the southern side of the western land-sea boundary and a small part of the northern land-sea boundary. IGF on the south side is significantly greater (up to $540 \mathrm{mV} / \mathrm{km}$ ) than that on the north side (up to $327 \mathrm{mV} / \mathrm{km}$ ); and IGF at the land-sea boundary on the east side and most of the north side is small. Under the north-south ionospheric current (Figure 9e), large-amplitude IGF is generated at the land-sea boundary area on the north and south sides of the eastern part of JDP; IGF on the south side is significantly larger (up to $506 \mathrm{mV} / \mathrm{km}$ ) than that on the north side (up to $175 \mathrm{mV} / \mathrm{km}$ ). In particular, IGF is extremely large on bay sea-land boundaries than on non-bay boundaries. The maximum IGF in bay boundaries is up to $540 \mathrm{mV} / \mathrm{km}$ compared to the maximum IGF of $270 \mathrm{mV} / \mathrm{km}$ in non-bay boundaries. The areas of larger IGF amplitudes (or coastal effect) are within the range of a few tens of kilometers along the coast and IGF in inland areas are significantly small, discussed in section 5 .

\section{Discussion}

As introduced in section 1, the variation of induced geoelectric field (IGF) in coastal areas have been studied earlier using different methods (Liu et al., 2009; Olsen \& Kuvshinov, 2004; Gilbert, 2005). For example, Liu et al. (2009) and Liu and Wang (2016) used a plane wave model and finite element 3-D conductivity model, respectively, to calculate the IGF variation in Guangdong (China) during the extreme geomagnetic storm in 09 November 2004. The 3-D model was found to have $18 \%$ better agreement with the measured data than the 1-D model. Honkonen and Kuvshinov (2018) developed a global 3-D conductivity model and calculated the distribution of IGF on a global scale under the action of the equivalent ionospheric current source computed by Pulkkinen et al. (2007). The results have shown that the IGF in mid and high latitude coastal areas is much larger compared to low latitudes. The maximum IGF in high latitudes can reach $2.5 \mathrm{~V} / \mathrm{km}$ and extends hundreds of kilometers inland.

In this paper we have developed a 3-D conductivity model based on the efficient finite element numerical calculation method (section 2). The model was used first (section 3) to show that the changes in 
lithospheric conductivity and ionospheric current (frequency, magnitude and direction) and ocean depth have major and minor effects, respectively, on IGF in coastal areas at mid latitudes. In coastal areas, IGF develops on the land side with maximum at the interface (IGFmax) due to the accumulation of electric charge on the less conductive land side. With conductivity increasing from 0.0001 to $0.1 \mathrm{~S} / \mathrm{m}$ (Figure 3 and Figure 4), IGFmax decreases from a high of $\sim 385 \mathrm{mV} / \mathrm{km}$ to a low of $24 \mathrm{mV} / \mathrm{km}$, and IGF rapidly decreases to $\sim 50 \%$ of IGFmax at $\sim 25-75 \mathrm{~km}$ and gradually stabilizes at a distances of $\sim 130-25 \mathrm{~km}$ from the interface. Earlier, Santosh et al. (2018) reported IGF stabilizing at a short distance of $15 \mathrm{~km}$ from the interface; this seems to be due to the use of huge current (1 MA) and finite difference time domain method. With ionospheric current frequency increasing from $0.002 \mathrm{~Hz}$ to $0.01 \mathrm{~Hz}$, IGFmax decreases from $\sim 150 \mathrm{mV} / \mathrm{km}$ to $50 \mathrm{mV} / \mathrm{km}$ (Figure 5 and Figure 6). With ionospheric current, magnitude of IGFmax is nearly equal to that of the current density, and IGFmax becomes strongest when the current is perpendicular to the sea-land interface (Figure 8). Earlier, by using an ionospheric current of frequency $0.001 \mathrm{~Hz}$ and density $1 \mathrm{~A} / \mathrm{m}$, Liu et al. (2017) obtained a much higher IGFmax of $2783 \mathrm{mV} / \mathrm{km}$; they used land and ocean conductivities of $0.01 \mathrm{~S} / \mathrm{m}$ and $4 \mathrm{~S} / \mathrm{m}$, respectively. With ocean depth, IGFmax decreases by a comparatively small amount ( 140 to $100 \mathrm{mV} / \mathrm{km}$ ) when the depth increases from $1 \mathrm{~km}$ to $5 \mathrm{~km}$ (Figure 9).

Then a realistic 3-D conductivity model of Jiaodong Peninsula (JDP) in China is constructed from measured data (Figure 10a), which is used to simulate the distribution of IGF in JDP under east-west and north-south ionospheric currents (section 4). The results (Figures 10b and 10e) indicate an important new aspect, that is, very strong coastal effect in bay areas. The maximum IGF in bay boundaries is up to 540 $\mathrm{mV} / \mathrm{km}$ compared to the maximum IGF of $270 \mathrm{mV} / \mathrm{km}$ in non-bay boundaries. This is due to the electric charge accumulating all around the curved low conducting landside of the bay. The IGF on the south coastal area of JDP, especially in bay areas, is generally stronger than that on the north (Figures $10 \mathrm{~b}$ and 10e). This may be because the topographic structure of the coastal area on the south side is more complicated than that on the north side. The sea-land boundary on the north side of the JDP is relatively smooth with no mountains and valleys, while the sea-land boundary on the south side is uneven. The electrical conductivity has multiple lateral abrupt changes in the uneven land-sea boundary, which has caused larger IGF in the coastal areas on the south side of the JDP compared to the north side. It is also found that the east-west and north-south ionospheric currents have different effects on the eastern and western coastal areas of JDP. This is because the sea-land boundary is perpendicular to the current. The land and sea boundaries in the western part of JDP are mostly north-south, and are greatly affected by the east-west ionospheric current. The eastern sea-land boundary is mostly east-west, and is greatly affected by the north-south ionospheric current.

\section{Conclusions}

By developing an earth electrical conductivity model based on finite element method we first modeled the effects of the factors affecting the induced geoelectric field (IGF) in a typical land-sea boundary region. The model has simulated the effects of the changes in lithospheric conductivity $(0.0001-0.1 \mathrm{~S} / \mathrm{m})$, 
ionospheric current (frequency $0.001-0.01 \mathrm{~Hz}$, density $50-200 \mathrm{~A} / \mathrm{m}^{2}$ and direction), and ocean depth (1-5 $\mathrm{km}$ ) on IGF generation in a typical mid latitude coastal area. The results show that the conductivity, ionospheric current frequency and current density have major effects and ocean depth has minor effect on IGF; and perpendicular current has greater effect than parallel current. The IGF develops on the land side of the interface. The IGF decreases rapidly from IGFmax at the interface to $50 \%$ of IGFmax at 25 $\mathrm{km}$ and then gradually decreases and stabilizes at $\sim 125 \mathrm{~km}$ inland.

Then by using measured data, we constructed a realistic 3-D conductivity model of China's Jiaodong Peninsula (JDP) and simulated the IGF variation under east-west and north-south ionospheric currents. The results show that geomagnetic field disturbances have greater impacts on the coastal area on the south side of the JDP than on the north side. The east-west ionospheric current has greater impact on the western coastal areas and north-south ionospheric current has greater impact on the eastern coastal areas. An important new aspect is the development of extremely large IGF in coastal bay areas. The results can provide a theoretical basis for the GIC risk assessment of JGP and other coastal areas during severe space weather events.

\section{Declarations}

\section{Acknowledgments}

Thanks to the China Geological Survey Geological Cloud website for the China Geological Environment Zoning Map, Shandong Province Geological Environment Zoning Map and China Deep Geoscience Section Map Dataset. Thanks to the COMSOL Multiphysics software provided by COMSOL Inc. for modeling and simulation.

\section{Authors' contributions}

Hong-Xu Chu modeled the earth conductivity model, simulated the geomagnetic field and induced geoelectric field, and wrote the manuscript. Zan-Yang Xing guided the modeling process and revised the model. Balan Nanan explained the results and corrected the manuscript. Yan-Ling Wang, Qing-He Zhang, Li-Kai Liang, and Han Wang helped for the discussions. All authors read and approved the fnal manuscript.

\section{Funding}

The work was supported by the National Natural Science Foundation of China (Grants 41904169, 42120104003, 41604139, and 41874170), the Foundation of China Research Institute of Radiowave Propagation (Grant A132101W02), and the Chinese Meridian Project.

\section{Availability of data and materials}

The modeling data used in this article are available at https://doi.org/10.5281/zenodo.5543865.The model and simulation data are available on the website 
of https://zenodo.org/record/5513720\#.YUwfPeziubg.

\section{Competing interests}

The authors declare that they have no competing interests.

\section{References}

1. Wang J X. Explosive solar activity and disastrous sapce weather. Journal of Purple Mountain Observatory, 2003, (01), 49-58

2. Clilverd M.A., Rodger, C. J., Brundell, J. B., et al. (2020), Geomagnetically induced currents and harmonic distortion: High time resolution case studies. Space Weather, 18(10). doi:10.1029/2020SW002594

3. Cui, M. D.,Liu, C. M., Liu, L. G. (2010), Assessment of the Influence caused by solar storm on Sichuan power grid rated $500 \mathrm{kV}$. High Voltage Technology, 36(11), 2849-2855.

4. Fernberg, P. A., Samson, C., Boteler, D. H., et al. (2007), Earth conductivity structures and their effects on geomagnetic induction in pipelines. Annales Geophysicae, 25(11), 207-218. doi:10.5194/angeo25-207-2007

5. Gilbert, J. L. (2005), Modeling the effect of the ocean-land interface on induced electric fields during geomagnetic storms. Space Weather, 3(4). doi:10.1029/2004SW000120

6. Honkonen, I., Kuvshinov, A., Rasttter, L., et al. (2018), Predicting global ground geoelectric field with coupled geospace and Three-Dimensional geomagnetic induction models. Space Weather, 16(8), 1028-1041. doi:10.1029/2018SW001859

7. Kappaenman, J. G. (1996), Geomagnetic storms and their impact on power systems. IEEE Power Engineering Review, 16(5). doi:10.1109/MPER.1996.491910

8. Kappaenman, J. G. (2003), Storm sudden commencement events and the associated geomagnetically induced current risks to ground-based systems at low-latitude and mid-latitude locations. Space Weather, 1(3). doi:10.1029/2003SW000009

9. Kappaenman, J. G., \& Albertson, V. D. (1990), Bracing for the geomagnetic storms. IEEE Spectrum, 27(3), 27-33. doi:10.1109/6.48847

10. Liu, C. M., Lin, C. X., Wang, X. N., et al. (2017), Influence of coast effect on geomagnetic induced current in power grid. Power System Technology, 41(8), 2716-2722.

11. Liu, C. M., Wang, X., Liu, L. G., et al. (2016), Calculation method of geomagnetic induced current in Power Grid Considering coast effect. Proceedings of the CSEE, 36(22), 6059-6066.

12. Liu, L. G., Liu, C. M., Zhang, B. (2009), Effects of geomagnetic storm on UHV power grids in China. Power System Technology, 33(11), 1-5.

13. Liu, L. G., Yang, P. H., Guo, S. X., et al. (2016), Impact of Geoelectric Field Direction and AC System Structure on Geomagnetically Induced Currents in \pm 800 kV Mengxi Convertor Station. Power System Technology, 40(5), 1295-1300. 
14. Ma, X, K. (2016), Electromagnetic field finite element and analytical combination method. Beijing: Science Press.

15. Marshall, R. A., Gorniak, H., Walt, T. V. D., et al. (2013), Observations of geomagnetically induced currents in the Australian power network. Space Weather, 11(1), 6-16. doi:10.1029/2012SW000849

16. Olsen, N., \& Kuvshinov, A. (2004), Modeling the ocean effect of geomagnetic storms. Earth Planets Space, 56(5), 525-530. doi:10.1186/BF03352512

17. Pulkkinen, A., Hesse, M., Kuznetsova, M., Rastatter, L. (2007), First-principles modeling of geomagnetically induced electromagnetic fields and currents from upstream solar wind to the surface of the Earth. Annales Geophysicae, 25(4), 881-893. doi:10.5194/angeo-25-881-2007

18. Pulkkinen, A., Lindahl, S., Viljanen, A., et al. (2005), Geomagnetic storm of 29-31 October 2003: Geomagnetically induced currents and their relation to problems in the Swedish high-voltage power transmission system. Space Weather, 3(8). doi:10.1029/2004SW000123

19. Santosh, P., Bach, N., Miguel, R., et al. (2018), A Finite Difference Time Domain Investigation of Electric Field Enhancements Along Ocean-Continent Boundaries During Space Weather Events. Journal of Geophysical Research: Space Physics, 123(6), 5033-5046. doi:10.1029/2017JA024648

20. Shigeru, F., Ikuko, F., Arata, F., et al. (2018), Numerical modeling of spatial profiles of geomagnetically induced electric field intensity in and around Japan. Technical Report of the Kakioka Magnetic Observatory, 14(2), 35-50.

21. Viljanen, A., Pulkkinen, A., Pirjola, R., et al. (2006), Recordings of geomagnetically induced currents and a nowcasting service of the Finnish natural gas pipeline system. Space Weather, 4(10). doi:10.1029/2006SW000234

22. Wang, H., Xing, Z.-Y., Balan, N., Wang, Y.-L., Zhang, Q.-H., \& Liang, L.-K. (2021). Simulation and analysis of geomagnetically induced current levels in Shandong Power Grid. Space Weather, 19, e2020SW002615. doi:10.1029/2020SW002615

23. Wang, J. X. (2003), Explosive solar activity and disastrous sapce weather. Journal of Purple Mountain Observatory, (01), 49-58.

24. Wu, W. L., \& Liu, L. G. (2013), Analysis of the influence of magnetic storm disturbance on the voltage of long distance high voltage transmission system. Science Technology and Engineeruing, 13(16), 4579-4584+4590.

25. Xu, Y. S. (2000), Research Progress on electrical conductivity of mantle minerals and rocks. Earth Science Frontiers, 7(1), 229-237.

\section{Figures}




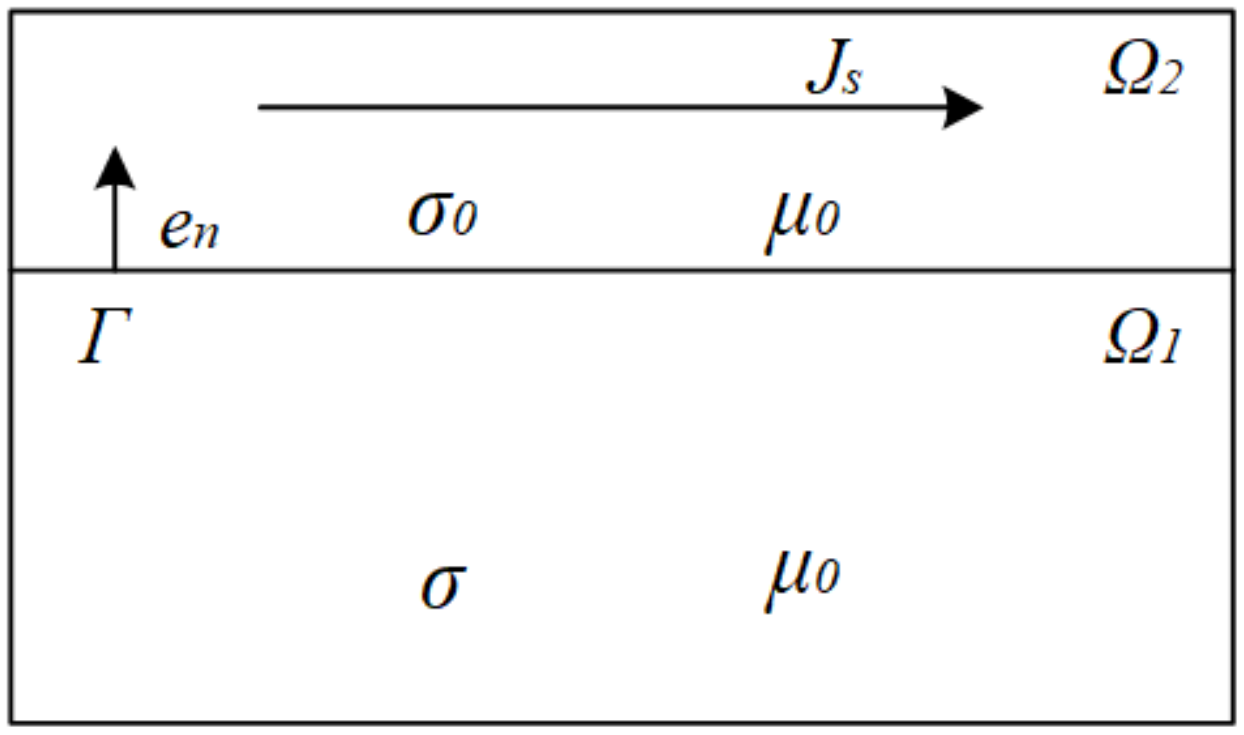

Figure 1

Mathematical model of induced geoelectric field (IGF).
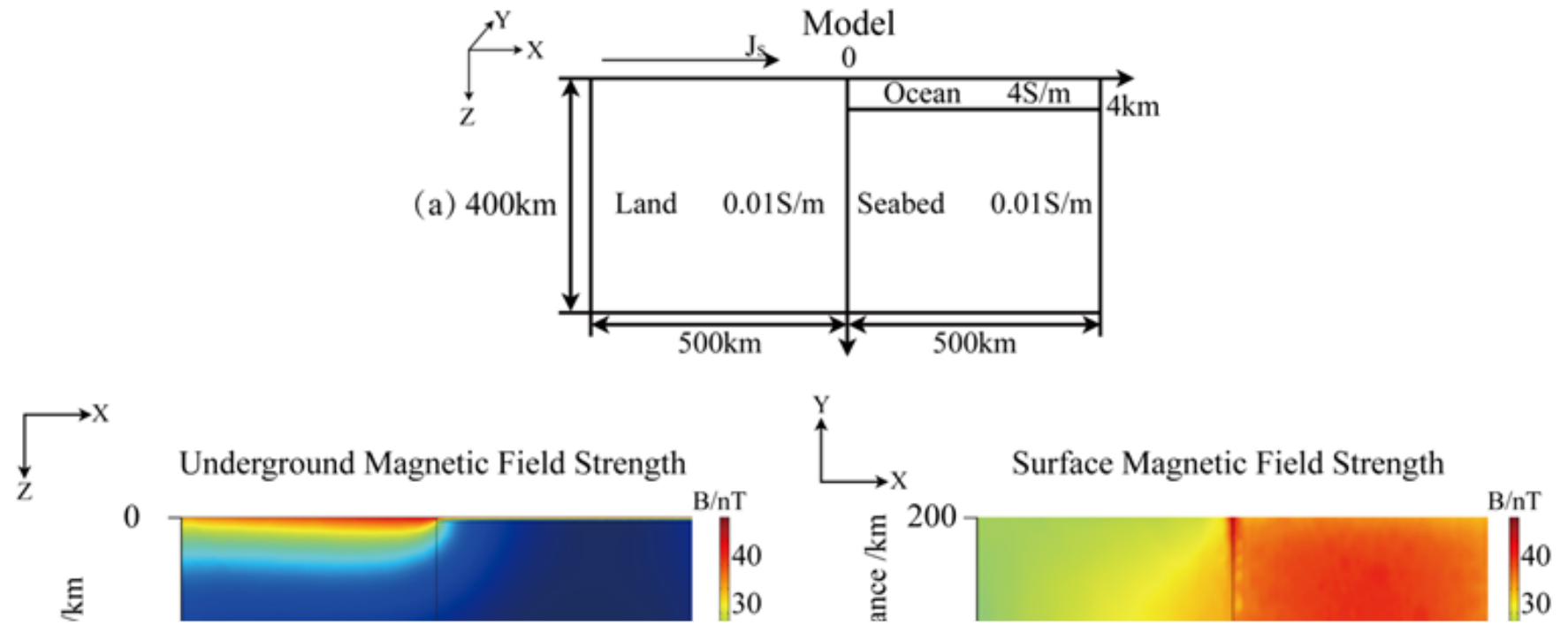
Figure 2

(a) Typical earth conductivity model of the land-sea boundary area, the ionospheric current $\mathrm{Js}$ is perpendicular to the sea-land boundary, the lithospheric conductivity is $0.01 \mathrm{~S} / \mathrm{m}$, the current density is $100 \mathrm{~A} / \mathrm{m}^{2}$, the current frequency is $0.003 \mathrm{~Hz}$, and the ocean depth is $4 \mathrm{~km}$. (b) and (c) display the underground magnetic field and IGF in $X-Z$ plane $(Y=0)$, and (d) and (e) display the surface magnetic field and IGF in the $X-Y$ plane $(Z=0)$.

\section{Underground Electric Field Strength}
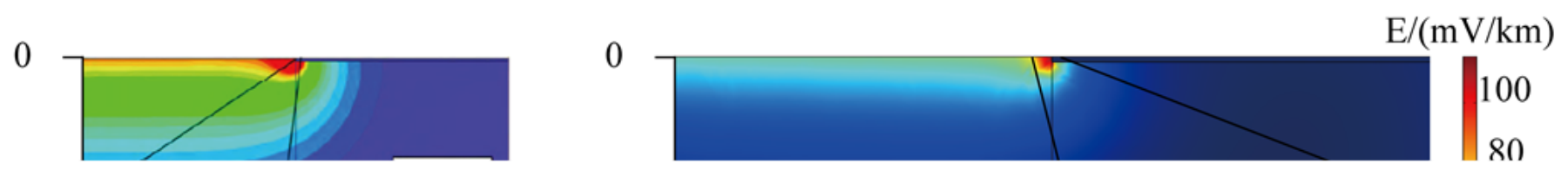

\section{Figure 3}

(a) The distribution of IGF calculated by Liu et al. (2017) under the conditions of earth conductivity $0.01 \mathrm{~S} / \mathrm{m}$, sea water conductivity $4 \mathrm{~S} / \mathrm{m}$, ocean depth $5 \mathrm{~km}$, sheet current $1 \mathrm{~A} / \mathrm{m}$, and frequency $0.001 \mathrm{~Hz}$. (b) is the same as Figure 2 (c), and the interface area in both (a) and (b) are enlarged in the inset for clarity. 

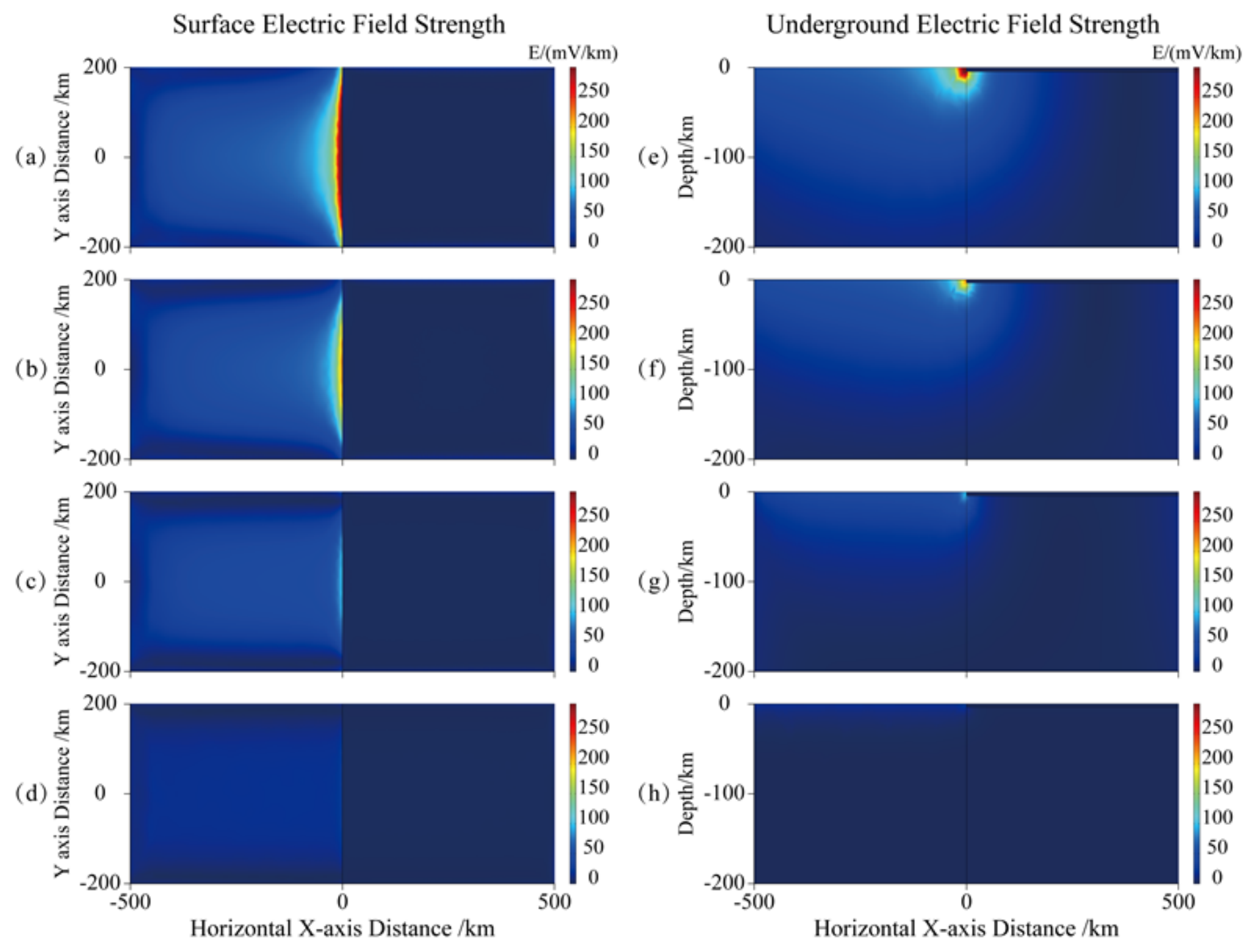

Figure 4

(a), (b), (c), (d) and (e), (f), (g), (h) show the distribution of surface IGF (X-Y plane with Z =0) and underground IGF ( $X-Z$ plane with $Y=0)$, respectively, when the lithospheric conductivity is $0.0001,0.001$, 0.01 and $0.1 \mathrm{~S} / \mathrm{m}$ (top to bottom). All other conditions are same as in the model (Figure 2a). 


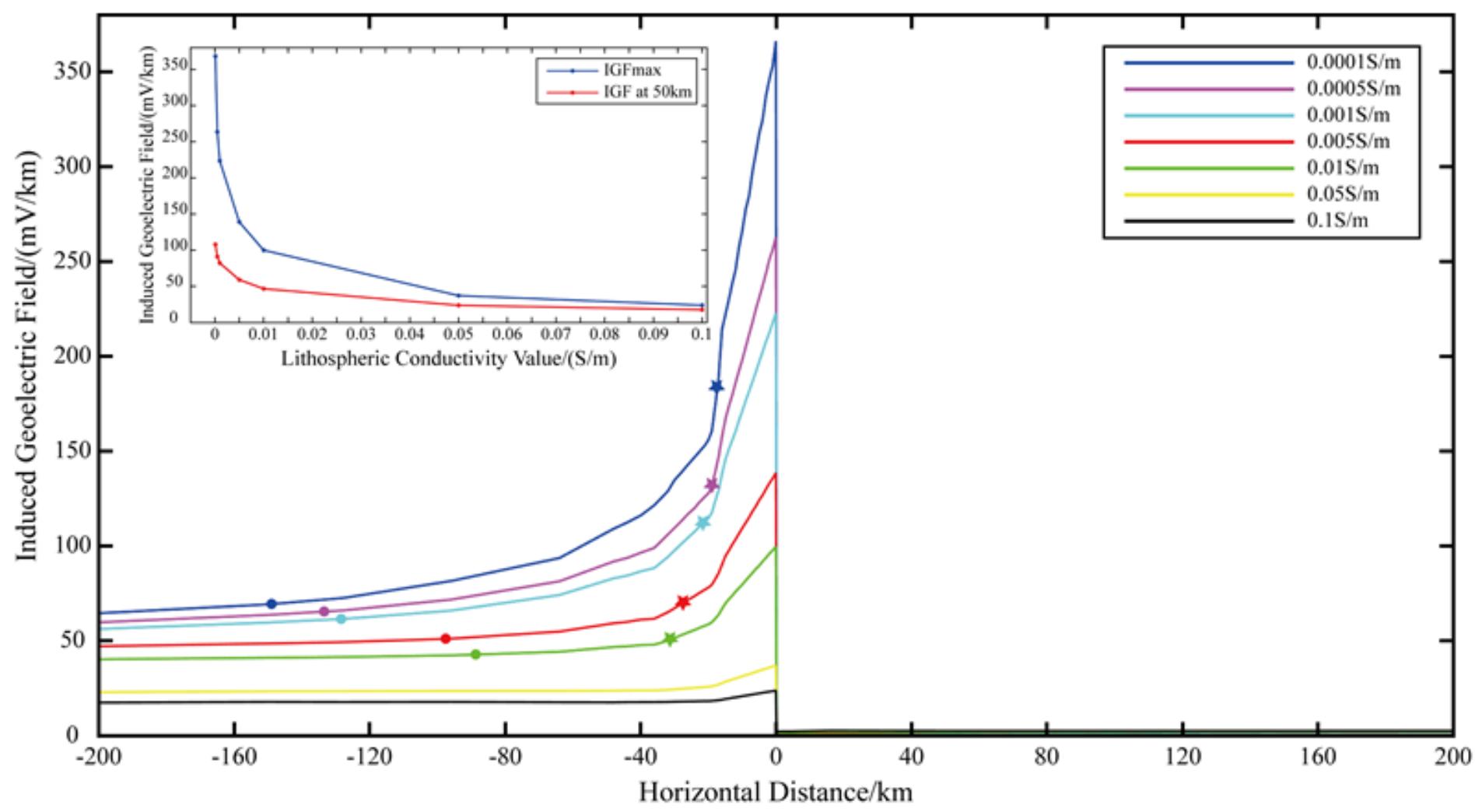

Figure 5

Variation of surface IGF with distance away from the interface for different lithospheric conductivity $(0.0001-0.1 \mathrm{~S} / \mathrm{m})$. Stars and dots indicate the distance where IGF becomes $50 \%$ of IGFmax and IGF nearly stabilizes, respectively, for $0.0001-0.01 \mathrm{~S} / \mathrm{m}$. Inset shows the variation of IGFmax (blue) and IGF at $50 \mathrm{~km}$ (red) away from the interface with lithospheric conductivity.

\section{Figure 6}

(a), (b), (c) and (d), (e), (f) show the distribution of surface IGF and underground IGF, respectively, when the ionospheric current frequency is $0.002 \mathrm{~Hz}, 0.006 \mathrm{~Hz}$ and $0.01 \mathrm{~Hz}$ (top to bottom). All other conditions are same as in the model (Figure 2a).

\section{Figure 7}

Variation surface IGF with distance away from the interface for different ionospheric current frequency (0.001-0.01 HZ). The inset in RHS shows variation of IGFmax (blue) and IGF at $50 \mathrm{~km}$ (red) away from the interface with ionospheric current frequency. 


\section{Surface Electric Field Strength}

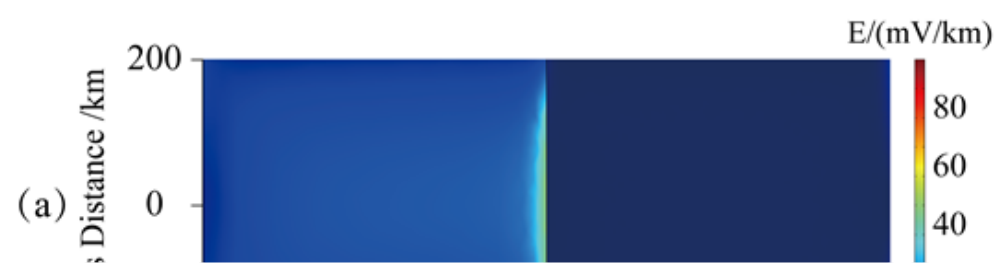

(b)

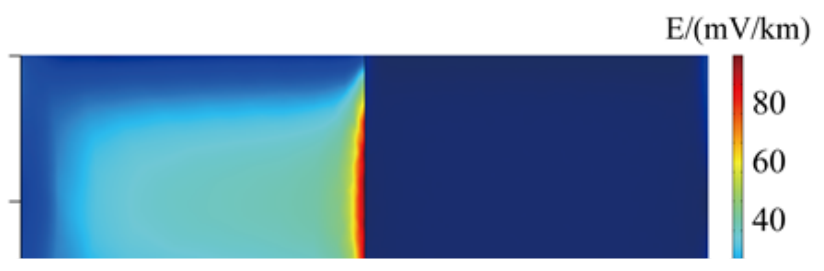

\section{Figure 8}

(a), (b) and (c) show the variation of surface IGF (X-Y plane, $Z=0$ ) for current density $50 \mathrm{~A} / \mathrm{m}^{2}, 100 \mathrm{~A} / \mathrm{m}^{2}$ and $200 \mathrm{~A} / \mathrm{m}^{2}$. (d) is similar to (b) but current density $100 \mathrm{~A} / \mathrm{m}^{2}$ is parallel to the interface. All other conditions are same as in the model (Figure 2a).

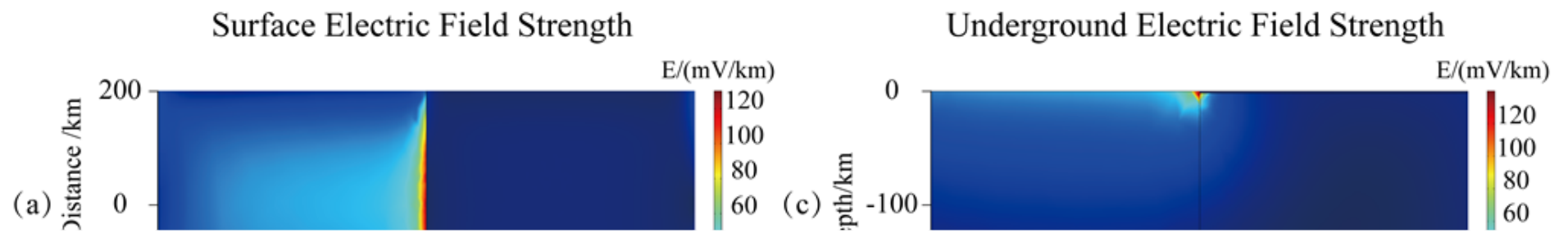

\section{Figure 9}

(a), (b) and (c) and (d) show the distribution of surface IGF and underground IGF, respectively, for ocean depth $1 \mathrm{~km}$ and $3 \mathrm{~km}$ respectively. All other conditions are same as in the model (Figure 2a). 


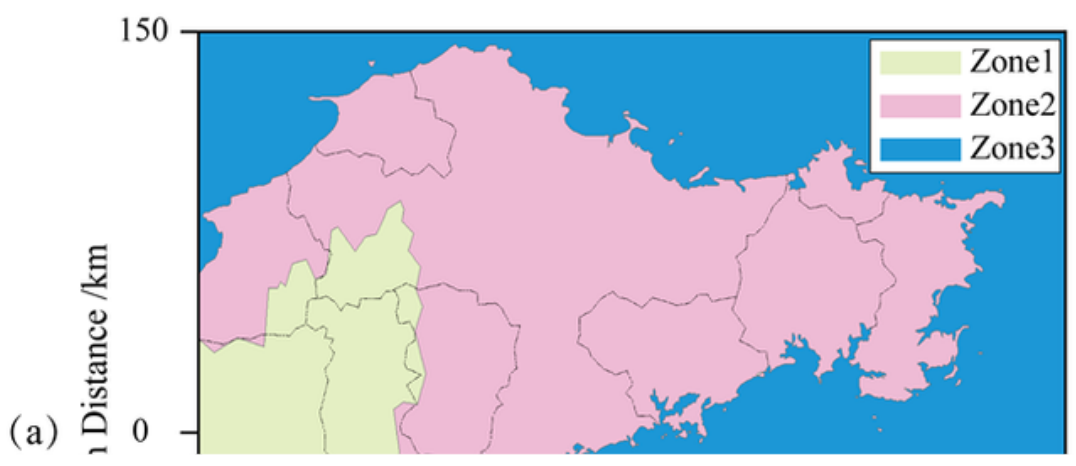

\section{Figure 10}

(a) Shows the electrical conductivity map of Jiaodong Peninsula (JDP) of China with list of the 3-D conductivity values. (b) and (c), and (d) and (e) are the distribution of the surface magnetic field and surface IGF simulated for eastward (top) and northward (bottom) ionospheric currents, respectively, in Jiaodong Peninsula (JDP). The results are found to be the same when the current directions are reversed. 